Polymer Journal Vol. 1, No. 1, pp. 71-81 (1970)

\title{
Conformation of Poly(N-Methyl Glycine) Random Chains
}

\author{
Seiji TANAKa and Akio NAKaJIMA \\ Department of Polymer Chemistry, Kyoto University Sakyo-ku, Kyoto, Japan.
}

(Received August 19, 1969)

\begin{abstract}
Theoretical calculations on the mean square unperturbed end-to-end length $\left\langle R_{0}{ }^{2}\right\rangle$ of poly(N-methyl glycine) chains in random coil form were carried out in accordance with presumed conformations of imide bonds in the chains. Two cases were taken into account: in the first case, all the imide bonds were assumed to be in trans conformation, and in the second case, a trans imide sequence was assumed to be interrupted by an isolated cis imide bond. In the former case, numerical calculations were carried out on two different approximations about nonbonded interactions by adopting the method used for poly- $\alpha$-L-amino acids with amide bonds all in trans conformation, and resulted in the unperturbed characteristic ratios of 1.46 and 1.53 for each case. In the latter case, a theoretical expression was proposed. These results on theoretical calculations were satisfactorily in accord with the experimental results.
\end{abstract}

KEY WORDS Polymer / Poly(N-Methyl Glycine) / Solution / Conformation / Unperturbed Dimension / Characteristic Ratio / Statistics of Chain Molecules /

The mean square unperturbed end-to-end length $\left\langle R_{0}^{2}\right\rangle$ of polypeptide chains in random coil form has been correlated with the chain structure by A. Brant and P. J. Flory ${ }^{1}$, using the method proposed by Lifson, ${ }^{2} \mathrm{Nagai}^{3}$, and Hoeve ${ }^{4}$ which treats the problem according to the one-dimensional Ising model ${ }^{5,6}$ developed for ferro magnetic substances. The characteristic ratio $\left\langle R_{0}{ }^{2}\right\rangle / n l^{2}$, in which $n$ is the number of trans peptide units and $l$ the length between successive $\alpha$-carbons, calculated by them was found ${ }^{7}$ to be in fair agreement with the experimental values on poly- $\alpha$-Lamino acids. Further, Flory and co-workers have offered some theoretical contributions on the characteristic ratios of polyglycine ${ }^{8}$, and polypeptide copolymers ${ }^{9,10}$ composed either of $\mathrm{L}$-alanine and glycine or of $\mathrm{D}$ - and L-alanine.

The calculated characteristic ratio $^{1}$ for poly$\alpha$-L-amino acids was $\left\langle R_{0}{ }^{2}\right\rangle / n l^{2}=9$, but that ${ }^{8}$ for polyglycine was $\left\langle R_{0}{ }^{2}\right\rangle / n l^{2}=2$. The less extended character of the polyglycine chain was concluded to result from the chain symmetry of this molecule.

In the chains of poly- $\alpha$-L-amino acids, the amide groups are planar and predominantly in the trans conformation, and thus the angle for rotation about an amide bond is assumed to be restricted to zero, which is characteristic of the trans con- formation. Accordingly, the rotation about two bonds lying between two adjacent amide bonds may interact, but the bond rotations within an amino acid residue can be assumed, if long-range interactions within a chain may be neglected, to be independent of the rotations in neighboring residues.

The polymer to be examined in this work is poly-N-substituted amino acid, and its chemical formula is written as $\left[-\mathrm{N}\left(\mathrm{CH}_{3}\right)-\mathrm{CH}_{2}-\mathrm{CO}\right]_{n}$. The molecular chain includes imide bonds in place of amide bonds of poly- $\alpha$-amino acids, and thus can not form intramolecular hydrogen bonds. Glazer and Rosenheck ${ }^{11}$ have suggested from ultraviolet spectra that this molecule was probably in random coil conformation in solution. Bovey, Ryan and Hood $^{12}$ have shown by nuclear magnetic resonance spectroscopy that the conformation of $\mathrm{N}$-acetylsarcosine methyl ester, a model compound for this polymer, is always strongly trans, but the preferred imide conformation of this polymer varies with the solvent employed. They recognized eight species of peptide triad sequences but have not yet made specific triad peak assignments. They estimated the energy difference between preferred and unpreferred triad sequences is as great as $1 \mathrm{kcal} / \mathrm{mol}$ in some cases. Presumably, the trans-trans-trans conformation would have the 
lowest potential energy.

In this paper, we shall first deal with the calculation of the characteristic ratio assuming the trans conformation for all imide groups. Then, secondly the effect of cis imide bonds on the unperturbed dimension will be discussed in connection with the chain structure and factors affecting the potentials for internal bond rotations.

\section{CALCULATION OF CHARACTERISTIC RATIO FOR CHAINS WITH ALL IMIDE GROUPS IN TRANS CONFORMATION}

\section{Estimation of Conformational Energy}

Structure of Poly-N-methyl Gycine

In Figure 1, a chain portion of a poly(N-methyl glycine) molecule is shown in its fully extended conformation, in which the $\mathrm{N}$-methyl residue is located as one of three $\mathrm{C}^{\mathrm{N}}-\mathrm{H}$ bonds eclipsing the imide $\mathrm{C}-\mathrm{N}$ bond. The bond lengths and bond angles used are those given in Tables I and II, respectively, and are assumed to be fixed. $\boldsymbol{l}_{i-1}$ and $\boldsymbol{l}_{i}$ denote the vectors of the virtual bonds connecting $\alpha$-carbons. The angles $\theta^{\prime}, \theta^{\prime \prime}$, and $\theta^{\prime \prime \prime}$ are the supplements of the associated bond angles given in Table II. The angles $\eta$ and $\xi$ are those between bond $\mathrm{C}_{i}{ }^{\alpha}-\mathrm{C}_{i}$ and virtual bond $\boldsymbol{l}_{i}$, and between bond $\mathrm{N}_{i-1}-\mathrm{C}_{i}{ }^{\alpha}$ and virtual bond $l_{i-1}$, respectively. Further, $\varphi$ and $\phi$ signify the angles of rotations about bond $\mathrm{N}-\mathrm{C}^{\alpha}$ and about bond $\mathrm{C}^{\alpha}-\mathrm{C}$, respectively. As mentioned above, the angle of rotation about the imide bond $\mathrm{C}-\mathrm{N}$ is assumed to be fixed at zero degree assigned for the trans conformation.

The bond co-ordinate system attached to each atom in the main chain is a right-handed rectangular co-ordinate, as employed by $\mathrm{Nagai}^{3}$ and Flory $e t a l .^{1} \quad$ The positive direction of the $x$ axis of the $i$-th co-ordinate system coincides with the

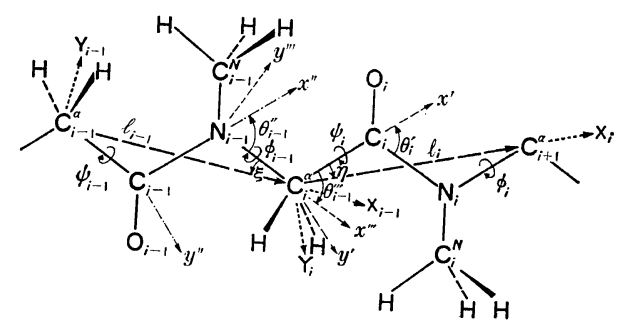

Figure 1. Fully extended, trans poly(N-methyl glycine) chain.
Table I. Bond lengths

\begin{tabular}{lcc}
\hline Bond & Bond vector & Bond length $(\AA)$ \\
\hline $\mathrm{C}^{\alpha}-\mathrm{C}$ & $\boldsymbol{l}^{\prime}$ & 1.53 \\
$\mathrm{C}-\mathrm{N}$ & $\boldsymbol{l}^{\prime \prime}$ & 1.32 \\
$\mathrm{~N}-\mathrm{C}^{\alpha}$ & $l^{\prime \prime \prime}$ & 1.47 \\
$\mathrm{~N}-\mathrm{C}^{\mathrm{N}}$ & $\boldsymbol{l}^{(\mathrm{N})}$ & 1.47 \\
$\mathrm{C}-\mathrm{O}$ & $\boldsymbol{l}^{(\mathrm{O})}$ & 1.24 \\
$\mathrm{C}^{\alpha}-\mathrm{H}$ & $\boldsymbol{l}^{\left(\mathrm{H}_{1}\right)}, \boldsymbol{l}^{\left(\mathrm{H}_{2}\right)}$ & 1.00 \\
$\mathrm{C}^{\mathrm{N}}-\mathrm{H}$ & $l^{(k)}(k=1,2,3)$ & 1.00 \\
\hline
\end{tabular}

Table II. Bond angles

\begin{tabular}{llcc}
\hline $\mathrm{CNC}^{\alpha}$ & $123^{\circ}$ & $\mathrm{HC}^{\alpha} \mathrm{N}$ & $109.5^{\circ}$ \\
$\mathrm{CNC}^{\mathrm{N}}$ & $123^{\circ}$ & $\mathrm{HC}^{\alpha} \mathrm{H}$ & $109.5^{\circ}$ \\
$\mathrm{HC}^{\mathrm{N} N}$ & $109.5^{\circ}$ & $\mathrm{HC}^{\alpha} \mathrm{C}$ & $109.5^{\circ}$ \\
$\mathrm{C}^{\alpha} \mathrm{NC}^{\mathrm{N}}$ & $114^{\circ}$ & $\mathrm{NC}^{\alpha} \mathrm{C}$ & $109.5^{\circ}$ \\
$\mathrm{C}^{\alpha} \mathrm{CN}$ & $114^{\circ}$ & $\eta$ & $22.23^{\circ}$ \\
$\mathrm{C}^{\alpha} \mathrm{CO}$ & $121^{\circ}$ & $\xi$ & $13.23^{\circ}$ \\
$\mathrm{NCO}$ & $125^{\circ}$ & & \\
\hline
\end{tabular}

$i$-th bond vector, that of the $y$ axis makes an acute angle with the $(i-1)$-th bond vector in the plane involving the $(i-1)$-th and $i$-th bond vectors, and that of the $z$ axis constitutes a right-handed rectangular co-ordinate system with the $x$ and $y$ axes. These co-ordinate systems are represented by $\left(x^{\prime}, y^{\prime}, z^{\prime}\right),\left(x^{\prime \prime}, y^{\prime \prime}, z^{\prime \prime}\right)$, and $\left(x^{\prime \prime \prime}, y^{\prime \prime \prime}, z^{\prime \prime \prime}\right)$. The same co-ordinate systems are also used for the virtual bonds connecting $\alpha$-carbons. The notations for axes are $X, Y$, and $Z$.

\section{Potential functions}

In accordance with the treatment given by Brant and Flory ${ }^{1}$, the potential function $V\left(\varphi_{i-1}, \phi_{i}\right)$ for rotations governing the mutual orientation of virtual bonds $i$ and $i-1$ is given by the sum of various contributions.

$V\left(\varphi_{i-1}, \phi_{i}\right)=V\left(\varphi_{i-1}\right)+V\left(\phi_{i}\right)+\sum_{j, k} V_{j k}\left(\varphi_{i-1}, \phi_{i}\right)$

$V\left(\varphi_{i-1}\right)$ and $V\left(\phi_{i}\right)$ denote the intrinsic threefold torsional potentials about bond $\mathrm{N}_{i-1}-\mathrm{C}_{i}{ }^{\alpha}$ and about bond $\mathrm{C}_{i}{ }^{\alpha}-\mathrm{C}_{i}$, respectively, and $\sum V_{i k}\left(\varphi_{i-1}, \phi_{i}\right)$ is the sum of interactions between all pairs of non-bonded atoms $j$ and $k$.

The term $V_{j k}\left(\varphi_{i-1}, \phi_{i}\right)$ is expressed by the sum of van der Waals interaction $V_{(W) j k}$ and electrostatic interaction $V_{(E) j k}$ between non-bonded atoms $j$ and $k$.

$$
V_{j k}\left(\varphi_{i-1}, \phi_{i}\right)=V_{(W) j k}+V_{(E) j k}
$$

Dipole interaction may be replaced by the electrostatic interaction appearing in Eq. 2 by 
distributing the charges on the atoms composing the dipole by means of vector decomposition.

For $V\left(\varphi_{i-1}\right)$ and $V\left(\phi_{i}\right)$, the same equations as used for poly- $\alpha$-amino acid by Brant and Flory ${ }^{1}$ were adopted

$$
\begin{gathered}
V\left(\varphi_{i-1}\right)=\frac{V_{0}\left(\varphi_{i-1}\right)}{2}\left[1-\cos 3 \varphi_{i-1}\right] \\
V_{0}\left(\varphi_{i-1}\right)=1.5(\mathrm{kcal} / \mathrm{mol}) \\
V\left(\phi_{i}\right)=\frac{V_{0}\left(\phi_{i}\right)}{2}\left[1-\cos 3 \phi_{i}\right] \\
V_{0}\left(\phi_{i}\right)=1.0(\mathrm{kcal} / \mathrm{mol})
\end{gathered}
$$

With regard to non-bonded atom interactions, we have considered the atom pairs which are separated by three or more bonds including $\mathrm{N}_{i-1}-\mathrm{C}_{i}{ }^{\alpha}$ and/or $\mathrm{C}_{i}{ }^{\alpha}-\mathrm{C}_{i}$. As mentioned earlier, we have also assumed that the rotation defined by $\varphi_{i}$ is independent of that by $\psi_{i}$, because of the trans assignment for the imide bond $\mathrm{C}_{i}-\mathrm{N}_{i}$.

For poly(N-methyl glycine), a total of 52 pair interactions involving carbonyl carbon, oxygen, imide nitrogen, methyl carbon, methyl hydrogens, and $\alpha$-hydrogens were taken into consideration (see Appendix). Calculations were carried out for the two cases shown below.

Case A: 25 atom pairs separated by three or four bonds.

Case B: 52 atom pairs covering all of the possible pairs separated by three, four, or five bonds.

Detailed information about these pairs is shown in Appendix Table VI, in which $\boldsymbol{l}^{\prime}, \boldsymbol{l}^{\prime \prime}, \boldsymbol{l}^{\prime \prime \prime}, \boldsymbol{l}^{(\mathrm{N})}$, $\boldsymbol{l}^{(\mathrm{O})}, \boldsymbol{l}^{\left(\mathrm{H}_{1}\right)}, \boldsymbol{l}^{\left(\mathrm{H}_{2}\right)}$, and $\boldsymbol{l}^{(k)}$ are the bond vectors given in Table 1, and $\boldsymbol{T}^{\prime}, \boldsymbol{T}^{\prime \prime}$, and $\boldsymbol{T}^{\prime \prime \prime}$ are the transformation matrices as shown in Eq. 13. Distance $r_{j k}$ between a given atom pair $j$ and $k$ was obtained from $h$, the sum of bond vectors, by

$$
r_{j k}=(\boldsymbol{h} \cdot \boldsymbol{h})^{1 / 2}
$$

The van der Waals interaction $V_{(W) j k}$ between atoms $j$ and $k$ was expressed by the Lennard-Jones type 6-12 potential function as a function of the separation of their centers $r_{j k}$.

$$
V_{(W) j k}=\frac{d_{j k}}{r_{j k}{ }^{12}}-\frac{e_{j k}}{r_{j k}{ }^{6}}
$$

The parameter $e_{j k}\left(\mathrm{kcal} \cdot \AA^{6} / \mathrm{mol}\right)$ was calculated in accordance with the Slater-Kirkwood equation.

$$
e_{j k}=\frac{(3 / 2) e\left(h / m^{1 / 2}\right) \alpha_{j} \alpha_{k}}{\left(\alpha_{j} / N_{j}\right)^{1 / 2}+\left(\alpha_{k} / N_{k}\right)^{1 / 2}}
$$

where, $e$ is the elementary electronic charge, $m$ the electronic mass, $\alpha$ the atomic polarizability, $h$ the Planck constant, and $N$ the effective number of electrons in the outer electronic subshell. The parameter $d_{j k}\left(\mathrm{kcal} \cdot \AA^{12} / \mathrm{mol}\right)$ was estimated by

$$
d_{j k}=\frac{e_{j k}\left(r_{\min }\right)^{6}}{2}
$$

in which, $r_{\min }$ denotes the atomic distance $(\AA)$ at which $V_{(W) j k}$ is minimum, and is assumed to be equal to the sum of the van der Waals radii of the interacting atoms. Here, the numerical values of $e_{j k}$ and $d_{j k}$ were cited from the paper by Scott and Scheraga ${ }^{13}$.

The electrostatic interaction energy was taken into consideration in the following way. To estimate the partial charge of atoms constituting the imide group, the bond moments for $\mathrm{O}=\mathrm{C}$, $\mathrm{C}-\mathrm{N}$, and $\mathrm{N}-\mathrm{CH}_{3}$ were used as given in Table III. Numerical values of bond moments for $\mathrm{O}=\mathrm{C}$ and $\mathrm{C}-\mathrm{N}$ were given the same values ${ }^{13}$ as in the amide residue. The bond moment of $\mathrm{N}-\mathrm{CH}_{3}$ was calculated from the dipole moment (3.79 Debye) of $\mathrm{CH}_{3} \mathrm{CON}\left(\mathrm{CH}_{3}\right)_{2}$ assuming planar conformation for this molecule. On the basis of these data, the electronic charge parameter $\delta_{j}$ of each atom was estimated as given in Table IV, in which the value for $\mathrm{C}^{\mathrm{N}}$ was calculated from the bond moment of $\mathrm{N}-\mathrm{CH}_{3}$ by assuming that the whole charge was located only at the $\mathrm{C}^{\mathrm{N}}$ atom.

Table III. Bond moment and bond distance

\begin{tabular}{ccc}
\hline Bond & $\begin{array}{c}\text { Bond distance } \\
(\AA)\end{array}$ & $\begin{array}{c}\text { Bond moment } \\
\text { (Debye units) }\end{array}$ \\
\hline $\mathrm{O}=\mathrm{C}$ & 1.24 & 2.48 \\
$\mathrm{C}-\mathrm{N}$ & 1.32 & 0.20 \\
$\mathrm{~N}-\mathrm{CH}_{3}$ & 1.47 & 2.43 \\
\hline
\end{tabular}

Table IV. Atomic charge

\begin{tabular}{lc}
\hline Atom & $\begin{array}{c}\text { (Electronic charge)/ } \\
\text { (Elementary charge) } \\
\delta_{j}\end{array}$ \\
\hline $\mathrm{O}$ & -0.416 \\
$\mathrm{C}$ & 0.448 \\
$\mathrm{~N}$ & -0.376 \\
$\mathrm{C}^{\mathrm{N}}$ & 0.344 \\
\hline
\end{tabular}




\section{S. TANAKA and A. NAKaJIMA}

Finally, the electrostatic interaction energy $V_{(E) j k}$ was obtained by the equation

$$
V_{(E) j k}=\frac{332.0 \delta_{j} \cdot \delta_{k}}{\varepsilon \cdot r_{j k}}
$$

in which, 332.0 is the constant for conversion from the Debye unit to the $\mathrm{kcal} / \mathrm{mol}$ unit, and $\varepsilon$ is the effective dielectric constant. In this paper, $\varepsilon=3.5$ was used according to Flory ${ }^{1}$. The interaction energy as given by Eq. 9 was summed up for all the charge atomic pairs for each conformation.

\section{Conformational Energy Contour Maps}

The conformational energy $V\left(\varphi_{i-1}, \psi_{i}\right)$ was calculated from Eqs. 1 and 2 for case $A$ and case B, at discrete values $0,30,60,90, \ldots \ldots, 300,330^{\circ}$ for $\varphi_{i-1}$ and $\psi_{i}$. The contour maps of conformational energy for case $\mathbf{A}$ and case $\mathbf{B}$ are shown in Figures 2 and 3. The symbol $\times$ denotes the lowest energy position. In Figure 2, this position appears at $\left(120^{\circ}, 120^{\circ}\right)$ and $\left(240^{\circ}, 240^{\circ}\right)$, and the energy value is as low as $-3.17 \mathrm{kcal} / \mathrm{mol}$. In the case of Figure 3, the lowest energy amounts $-0.28 \mathrm{kcal} / \mathrm{mol}$ and the lowest energy point appears at $\left(120^{\circ}, 240^{\circ}\right)$ and $\left(240^{\circ}, 120^{\circ}\right)$. The appearance of these two contour maps is considerably different, but, as will be shown later,

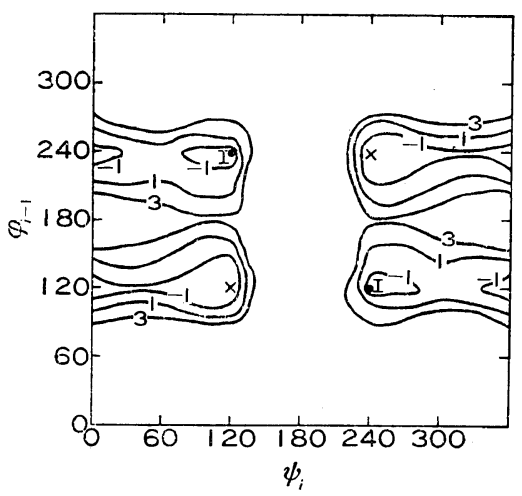

Figure 2. Contour map of the conformational energy of the poly(N-methyl glycine) chain with all imide bonds in trans conformation as calculated from Eqs. 1 and 2 taking into account threeand four-bond interactions. The absolute minimum at $\times$ orresponds to $-3.17 \mathrm{kcal} / \mathrm{mol}$. The contour interval is $1 \mathrm{kcal} / \mathrm{mol}$ residue. The minimum I corresponds to $-1.97 \mathrm{kcal} / \mathrm{mol}$.

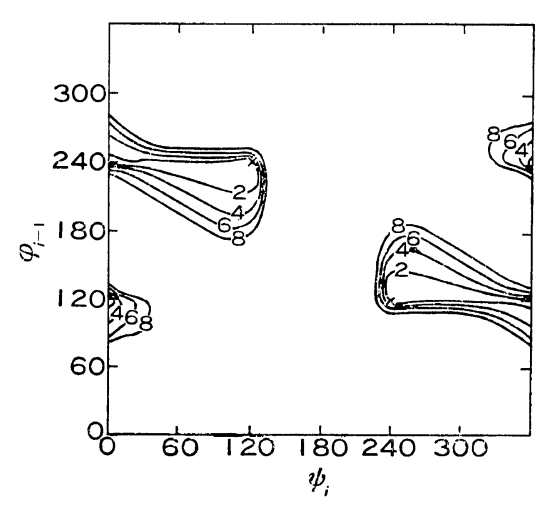

Figure 3. Contour map of the conformational energy of the poly( $\mathrm{N}$-methyl glycine) chain with all imide bonds in trans conformation as calculated from Eqs. 1 and 2 taking into account all possible nonbonded interactions. The absolute minimum at $\times$ corresponds to $-0.28 \mathrm{kcal} / \mathrm{mol}$.

numerical values of the characteristic rat!o calculated on the basis of these two cases do not differ significantly (1.46 for case $\mathrm{A}$, and 1.53 for case B).

\section{Mean Square Unperturbed End-to-End Distance}

The unperturbed characteristic ratio $\left\langle R_{0}{ }^{2}\right\rangle / n l^{2}$ of poly( $\mathrm{N}$-methyl glycine) may be evaluated with the method proposed by Flory and co-workers ${ }^{1,7}$.

Let us consider that a molecule consists of $n$ virtual bonds. Let the right-handed Cartesian coordinate system affixed to $i$-th virtual bond be $\left(X_{i}, Y_{i}, Z_{i}\right)$, as shown in Figure 1 . The matrix $\boldsymbol{T}_{i-1}$ transforming the coordinate system $\left(X_{i}, Y_{i}\right.$, $\left.Z_{i}\right)$ to the coordinate system $\left(X_{i-1}, Y_{i-1}, Z_{i-1}\right)$ is given by

$$
\boldsymbol{T}_{i-1}=\boldsymbol{T}_{\xi} \boldsymbol{T}_{\theta} \boldsymbol{T}_{\eta}
$$

where the matrices $\boldsymbol{T}_{\xi}, \boldsymbol{T}_{\theta}$, and $\boldsymbol{T}_{\eta}$ are as follows ${ }^{1}$.

$$
\begin{aligned}
\boldsymbol{T}_{\eta}= & \boldsymbol{T}\left(-\eta, \phi_{i}+\pi\right) \\
= & {\left[\begin{array}{llr}
\cos \eta & -\sin \eta & 0 \\
\sin \eta \cos \phi_{i} & \cos \eta \cos \phi_{i} & -\sin \phi_{i} \\
\sin \eta \sin \phi_{i} & \cos \eta \sin \phi_{i} & \cos \phi_{i}
\end{array}\right] } \\
& \boldsymbol{T}_{\xi}=\boldsymbol{T}(\xi, \pi)=\left[\begin{array}{rrr}
\cos \xi & \sin \xi & 0 \\
-\sin \xi & \cos \xi & 0 \\
0 & 0 & 1
\end{array}\right]
\end{aligned}
$$


Conformation of Poly(N-Methyl Glycine) Random Chains

$$
\boldsymbol{T}_{\theta}=\boldsymbol{T}\left(\theta_{i-1}^{\prime \prime \prime}, \varphi_{i-1}\right)=\left[\begin{array}{lcc}
\cos \theta_{i-1}^{\prime \prime \prime} & \sin \theta_{i-1}^{\prime \prime \prime} & 0 \\
\sin \theta_{i-1}^{\prime \prime \prime} \cos \varphi_{i-1} & -\cos \theta_{i-1}^{\prime \prime \prime} \cos \varphi_{i-1} & \sin \varphi_{i-1} \\
\sin \theta_{i-1}^{\prime \prime \prime} \sin \varphi_{i-1} & -\cos \theta_{i-1}^{\prime \prime \prime} \sin \varphi_{i-1} & -\cos \varphi_{i-1}
\end{array}\right]
$$

The unperturbed end-to-end distance $\left\langle R_{0}{ }^{2}\right\rangle$ of the chain is generally expressed by

$$
\left\langle\boldsymbol{R}_{0}{ }^{2}\right\rangle=n l^{2}+2 \sum_{i=1}^{n-1} \sum_{j=i+1}^{n} \boldsymbol{l}_{i}\left\langle\boldsymbol{T}_{i} \boldsymbol{T}_{i+1} \ldots \boldsymbol{T}_{j-1}\right\rangle \boldsymbol{l}_{j}
$$

and is simplified for the present system as

$$
\frac{\left\langle\boldsymbol{R}_{0}{ }^{2}\right\rangle}{n l^{2}}=1+\frac{2}{n l^{2}} \sum_{i=1}^{n-1} \sum_{j=i+1}^{n} \boldsymbol{l}_{i} \prod_{h=i}^{j-1}\left\langle\boldsymbol{T}_{h}\right\rangle \boldsymbol{l}_{j}
$$

Therefore, evaluation of the characteristic ratio is reduced to the calculation of the statistical mechanical average $\left\langle\boldsymbol{T}_{i}\right\rangle$ of the matrix $\boldsymbol{T}_{i}$. That is,

$$
\left\langle\boldsymbol{T}_{i-1}\right\rangle=\frac{\int_{0}^{2 \pi} \int_{0}^{2 \pi} \boldsymbol{T}_{i-1}\left(\varphi_{i-1}, \phi_{i}, \theta_{i-1}^{\prime \prime \prime}, \xi, \eta\right) \exp \left[-\frac{V\left(\varphi_{i-1}, \phi_{i}\right)}{R T}\right] d \varphi_{i-1} d \phi_{i}}{\int_{0}^{2 \pi} \int_{0}^{2 \pi} \exp \left[-\frac{V\left(\varphi_{i-1}, \phi_{i}\right)}{R T}\right] d \varphi_{i-1} d \phi_{i}}
$$

where, $\theta_{i-1}^{\prime \prime \prime}, \xi$, and $\eta$ are constants as shown in Table II. In practical calculation, the integral was replaced by the summation. $\boldsymbol{T}_{\xi}$ is independent of $\varphi_{i-1}$ and $\psi_{i}$, so $\left\langle\boldsymbol{T}_{i-1}\right\rangle$ is written as

$$
\left\langle\boldsymbol{T}_{i-1}\right\rangle=\boldsymbol{T}_{\xi}\left\langle\boldsymbol{T}_{\theta} \boldsymbol{T}_{\eta}\right\rangle
$$

Next we considered a $12 \times 12$ matrix $U$, in which the elements were $\exp \left[-V\left(\varphi_{i-1}, \phi_{i}\right) / R T\right]$, with rows indexed by 12 discrete values of $\varphi_{i-1}\left(\varphi_{i-1}=\right.$ $\left.0,30,60,90, \ldots \ldots, 300,330^{\circ}\right)$ and columns indexed by 12 discrete values of $\phi_{i}\left(\psi_{i}=0,30\right.$, $\left.60,90, \ldots \ldots, 300,330^{\circ}\right)$. The temperature chosen was $T=310^{\circ} \mathrm{K}$. Defining $J$ as the $12 \times 1$ column matrix with all elements unity and $J^{T}$ as the transpose of $J$, we obtained the conformational partition function $Z$ by the equation

$$
Z=\boldsymbol{J}^{T} \boldsymbol{U} \boldsymbol{J}
$$

where

$$
\boldsymbol{J}^{T}=(1,1,1, \ldots, 1) .
$$

From $\boldsymbol{U}$ a diagonal matrix $\boldsymbol{U}^{*}$ of the order 36 was constructed by taking the direct product of the unit matrix $\boldsymbol{E}$ of the order 3 with $\boldsymbol{U}$.

$$
\boldsymbol{U}^{*}=\boldsymbol{E} \times \boldsymbol{U}=\left[\begin{array}{lll}
\boldsymbol{U} & \boldsymbol{O} & \boldsymbol{O} \\
\boldsymbol{O} & \boldsymbol{U} & \boldsymbol{O} \\
\boldsymbol{O} & \boldsymbol{O} & \boldsymbol{U}
\end{array}\right]
$$

Further, nine diagonal matrices $\boldsymbol{T}_{\theta, v s}$ of the order 12 were defined with elements given by the vs. element of matrix $\boldsymbol{T}_{\theta}$ [Eq. 13]. For example, with $v=1$ and $s=1$, it is expressed as

$$
\boldsymbol{T}_{\theta, 11}=\left[\begin{array}{ccc}
\cos \theta & & \boldsymbol{O} \\
\cos \theta & & \\
& \ddots & \\
\boldsymbol{O} & & \cos \theta
\end{array}\right]
$$

Finally, we constructed a matrix $\boldsymbol{T}_{\theta}{ }^{*}$ of the order 36 composed of these nine diagonal matrices $\boldsymbol{T}_{\theta, v s}$

$$
\boldsymbol{T}_{\theta}^{*}=\left[\begin{array}{lll}
\boldsymbol{T}_{\theta, 11} & \boldsymbol{T}_{\theta, 12} & \boldsymbol{T}_{\theta, 13} \\
\boldsymbol{T}_{\theta, 21} & \boldsymbol{T}_{\theta, 22} & \boldsymbol{T}_{\theta, 23} \\
\boldsymbol{T}_{\theta, 31} & \boldsymbol{T}_{\theta, 32} & \boldsymbol{T}_{\theta, 33}
\end{array}\right]
$$

In a similar manner, nine diagonal matrices $\boldsymbol{T}_{\eta, v s}$ of the order 12 were defined with elements given by the $v s$. element of the matrix $\boldsymbol{T}_{\eta}$ [Eq. 11]. And from these nine matrices a matrix $\boldsymbol{T}_{\eta}{ }^{*}$ was constructed.

$$
\boldsymbol{T}_{\eta}^{*}=\left[\begin{array}{lll}
\boldsymbol{T}_{\eta, 11} & \boldsymbol{T}_{\eta, 12} & \boldsymbol{T}_{\eta, 13} \\
\boldsymbol{T}_{\eta, 21} & \boldsymbol{T}_{\eta, 22} & \boldsymbol{T}_{\eta, 23} \\
\boldsymbol{T}_{\eta, 31} & \boldsymbol{T}_{\eta, 32} & \boldsymbol{T}_{\eta, 33}
\end{array}\right]
$$

Now, defining $\boldsymbol{J}^{*}$ by $\boldsymbol{J}^{*}=\boldsymbol{E} \times \boldsymbol{J}$ and $\boldsymbol{J}^{* T}=$ $\boldsymbol{E} \times \boldsymbol{J}^{T}$, we arrived $\mathrm{at}^{1}$

$$
\left\langle\boldsymbol{T}_{i-1}\right\rangle=Z^{-1} \boldsymbol{T}_{\xi} \boldsymbol{J}^{* T} \boldsymbol{T}_{\theta}{ }^{*} \boldsymbol{U}^{*} \boldsymbol{T}_{\eta}{ }^{*} \boldsymbol{J}^{*}
$$

Thus, the characteristic ratio $\left\langle R_{0}{ }^{2}\right\rangle / n l^{2}$ can be evaluated by the equation 


$$
\frac{\left\langle\boldsymbol{R}_{0}{ }^{2}\right\rangle}{n l^{2}}=\left\{\frac{\boldsymbol{E}+\langle\boldsymbol{T}\rangle}{\boldsymbol{E}-\langle\boldsymbol{T}\rangle}-\frac{2}{n}\langle\boldsymbol{T}\rangle \frac{\boldsymbol{E}-\langle\boldsymbol{T}\rangle^{n}}{(\boldsymbol{E}-\langle\boldsymbol{T}\rangle)^{2}}\right\}_{11}
$$

where subscript 11 denotes the $(1,1)$ element of the matrix.

\section{Numerical Results}

The numerical results of the averaged matrix $\langle\boldsymbol{T}\rangle$ calculated from the conformational energy for case A (Figure 2) were

$$
\langle\boldsymbol{T}\rangle=\left[\begin{array}{rrr}
0.218 & 0.047 & 0.000 \\
-0.403 & 0.372 & 0.000 \\
0.001 & 0.000 & 0.000
\end{array}\right]
$$

and those for case B (Figure 3) were

$$
\langle\boldsymbol{T}\rangle=\left[\begin{array}{rrr}
0.154 & -0.193 & -0.416 \\
-0.747 & -0.397 & 0.466 \\
-0.207 & -0.543 & 0.303
\end{array}\right]
$$

With the use of the values given by Eqs. 26 and 27 , we arrived at the final results.

$$
\begin{array}{ll}
\frac{\left\langle R_{0}{ }^{2}\right\rangle}{n l^{2}}=1.46 & \text { for case } \mathrm{A} \\
\frac{\left\langle R_{0}{ }^{2}\right\rangle}{n l^{2}}=1.53 & \text { for case } \mathrm{B}
\end{array}
$$

We shall now compare these characteristic ratios with those obtained from the free rotation model for vitual bonds (in this case, all the imide bonds are assumed to be fixed at trans conformation).

According to Crewther ${ }^{14}$, the unperturbed dimension $\left\langle R_{0}{ }^{2}\right\rangle_{f}$ for such a model is given by

$$
\left\langle R_{0}{ }^{2}\right\rangle_{f}=27.9 n-20.3
$$

which leads to a characteristic ratio of

$$
\frac{\left\langle R_{0}{ }^{2}\right\rangle_{f}}{n l^{2}}=1.93
$$

with $l=3.80 \AA$. The molecular parameters used by us in the foregoing calculation were somewhat different from those used by Crewther. The characteristic ratio for free rotation was also obtained from our equation by calculating the averaged matrix $\langle\boldsymbol{T}\rangle_{f}$ under an assumption that all the statistical weights in the matrix $U$ were the same. Such an assumption yielded

$$
\langle\boldsymbol{T}\rangle_{f}=\left[\begin{array}{rrr}
0.301 & -0.123 & 0.000 \\
-0.071 & 0.029 & 0.000 \\
0.000 & 0.000 & 0.000
\end{array}\right]
$$

and led to

$$
\frac{\left\langle R_{0}{ }^{2}\right\rangle_{f}}{n l^{2}}=1.89
$$

The numerical value 1.89 shown in Eq. 33 is in good agreement with the value obtained by Crewther.

\section{EFFECT OF cis IMIDE CONFORMATION ON CHARACTERISTIC RATIO}

As mentioned above, Bovey and co-workers ${ }^{12}$ have suggested the existence of cis imide conformation besides trans imide conformation for poly(N-methyl glycine) from the NMR experiments in various kinds of solvent.

In the infrared analysis on $\mathrm{N}$-methyl amide carried out by $\mathrm{Suzuki}^{15}$, the energy difference between cis and trans amide was estimated as 1 to $3 \mathrm{kcal} / \mathrm{mol}$, and its energy barrier was quite high. However, as mentioned earlier, only little is known about the imide bond. In the NMR study ${ }^{12}$ on $\mathrm{N}$-acetylsarcosine methyl ester, it was pointed out that the exchange between trans and cis was slow and so each conformer gave sharp peaks. Accordingly, trans $\rightleftarrows$ cis mutarotation was presumed not to take place so easily. Thus, it may be permissible to consider that the imide bond behaves like double bonds in nature. On this premise, imide bonds can be treated independently; i.e., interactions between rotations relating to $\phi_{i-1}^{\prime \prime}$ and $\varphi_{i}$, and between rotations relating to ${\psi_{i}}^{\prime}$ and ${\psi_{i}}_{i}^{\prime \prime}$ (Figure 4) may be treated independently. However, the following interactions, in the case of cis imide in between two trans imide units, were not neglected. These were the interactions between $\mathrm{H}$ atoms attached to $\mathrm{C}_{i-1}^{\alpha}$ and $\mathrm{H}$ atoms attached to $\mathrm{C}_{i}{ }^{\alpha}$, those between $\mathrm{H}$ atoms attached to the $C_{i-1}^{\alpha}$ and $C_{i}{ }^{\alpha}$ atom, and those between $\mathrm{H}$ atoms attached to the $\mathrm{C}_{i}^{\alpha}$ and $\mathrm{C}_{i-1}^{\alpha}$ atom.

\section{Formulation}

Figure 4 shows a portion of a poly(N-methyl glycine) chain with a cis imide bond in it. It should be noted that the notations in this figure are different from those used in Figure 1. Since the imide bond was assumed to exist either in trans or cis conformations, interactions were likely to be different in accordance with trans $\left(\psi^{\prime \prime}=0\right)$ or cis $\left(\psi^{\prime \prime}=180^{\circ}\right)$ conformations. The interactions are schematically represented as follows, (the arrows signifying the interactions) 
Conformation of Poly(N-Methyl Glycine) Random Chains

(1)
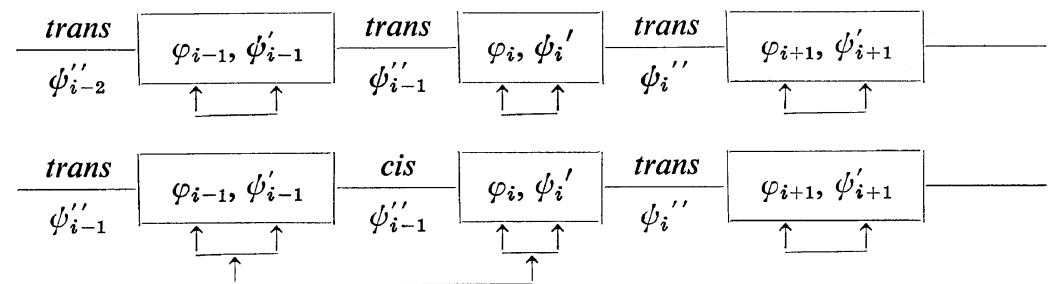

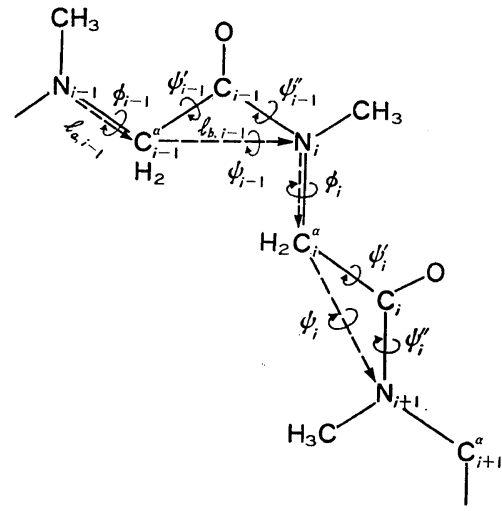

Figure 4. Presence of a cis imide bond in poly(Nmethyl glycine) chain.

In the present treatment, the succession of cis imide bonds is not taken into account from energy considerations. In the case of (1), the interaction associated with $\left(\varphi_{i}, \phi_{i}{ }^{\prime}\right)$ is independent of that in the neighboring pairs $\left(\varphi_{i-1}, \phi_{i-1}^{\prime}\right)$ and $\left(\varphi_{i+1}, \phi_{i+1}^{\prime}\right)$. This case has already been treated above. In case (2), however, additional interactions as related to the interaction energies $V\left(\varphi_{i-1}\right.$, $\left.\psi_{i-1}^{\prime}, \psi_{i-1}^{\prime \prime}, \varphi_{i}\right)$ and $V\left(\psi_{i-1}^{\prime}, \psi_{i-1}^{\prime \prime}, \varphi_{i}, \psi_{i}^{\prime}\right)$ should be taken into account. As mentioned above, these energies originate mainly from the interactions between the $\left(\mathrm{C}_{i-1}^{\alpha}-\mathrm{H}_{2}\right)$ group and the $\left(\mathrm{H}_{2-}\right.$ $\mathrm{C}_{i}{ }^{\alpha}$ ) group, and thus may be composed of two terms, i.e.

$$
\begin{aligned}
& V\left(\varphi_{i-1}, \phi_{i-1}^{\prime}, \phi_{i-1}^{\prime \prime}, \varphi_{i}\right) \\
& \quad=V\left(\varphi_{i-1}, \phi_{i-1}^{\prime}, \phi_{i-1}^{\prime \prime}\right)+V\left(\psi_{i-1}^{\prime}, \phi_{i-1}^{\prime \prime}, \varphi_{i}\right) \\
& V\left(\psi_{i-1}^{\prime}, \psi_{i-1}^{\prime \prime}, \varphi_{i}, \phi_{i}^{\prime}\right) \\
& \quad=V\left(\psi_{i-1}^{\prime}, \phi_{i-1}^{\prime \prime}, \varphi_{i}\right)+V\left({\psi_{i-1}^{\prime}}^{\prime \prime}, \varphi_{i},{\phi_{i}}^{\prime}\right)
\end{aligned}
$$

As shown in Figure 4, let $\boldsymbol{l}_{a, i-1}$ and $\boldsymbol{l}_{b, i-1}$ be the bond vectors of the $\mathrm{N}_{i-1}-\mathrm{C}_{i-1}^{\alpha}$ bond and of the virtual bond connecting $\mathrm{C}_{i-1}^{\alpha}$ and $\mathrm{N}_{i}$, respectively, and let $\varphi_{i-1}$ and $\psi_{i-1}$ be the rotational angles about the $\mathrm{N}_{i-1}-\mathrm{C}_{i-1}^{\alpha}$ bond and that virtual bond, respectively. $\psi_{i-1}$ is a function of both $\psi_{i-1}^{\prime}$ and $\phi_{i-1}^{\prime \prime}$, but is treated as a function of only $\psi_{i-1}^{\prime}$, because $\psi_{i-1}^{\prime \prime}$ is fixed at $\psi_{i-1}^{\prime \prime}=0$ (trans) or $\phi_{i-1}^{\prime \prime}=180^{\circ}$ (cis). Therefore, we can treat the interaction energy $V(\psi, \varphi)$ in a similar manner as before, with fixed $\psi^{\prime \prime}$ at trans or cis conformations.

Altering the treatment of the imide bond in the chain as used in the preceding section, thereafter, we treated the imide bond independently; for example, the term $V\left(\varphi_{i-1}, \phi_{i-1}^{\prime}, \phi_{i-1}^{\prime \prime}\right)$ in Eq. 34 was written as follows.

$$
\begin{aligned}
V\left(\varphi_{i-1}, \phi_{i-1}\right) & =V\left(\varphi_{i-1}, \phi_{i-1}^{\prime}, \phi_{i-1}^{\prime \prime}\right) \\
& =V\left(\phi_{i-1}^{\prime}\right)+V\left(\varphi_{i-1}, \phi_{i-1}^{\prime}\right)
\end{aligned}
$$

in which $V\left(\psi_{i-1}^{\prime}\right)$ and $V\left(\varphi_{i-1}, \psi_{i-1}^{\prime}\right)$ respectively signified the sum of non-bonded interaction energies about $\psi_{i-1}^{\prime}$ and about $\left(\varphi_{i-1}, \psi_{i-1}^{\prime}\right)$.

We then applied the method proposed by Lifson $^{2}$ and Nagai $^{3}$. For example, with regard to the interaction about $\left(\varphi_{i-1}, \psi_{i-1}\right)$, we took into account the following matrix.

$$
\boldsymbol{U}(\varphi, \phi)=\boldsymbol{u}_{12}\left(\varphi, \phi^{\prime}\right) \boldsymbol{u}_{1}\left(\psi^{\prime}\right)
$$

where

$$
\begin{aligned}
& \boldsymbol{u}_{12}=\left[\begin{array}{ccc}
\boldsymbol{u}\left(\varphi^{(1)}, \phi^{\prime(1)}\right) & \cdots & \boldsymbol{u}\left(\varphi^{(1)}, \phi^{\prime(r)}\right) \\
\vdots & & \vdots \\
\boldsymbol{u}\left(\varphi^{(r)}, \phi^{\prime(1)}\right) & \cdots & \boldsymbol{u}\left(\varphi^{(r)}, \phi^{\prime(r)}\right)
\end{array}\right] \\
& \boldsymbol{u}_{1}=\left[\begin{array}{ccc}
\boldsymbol{u}\left(\phi^{\prime(1)}\right) & & \boldsymbol{O} \\
& \cdot & \cdot \\
\boldsymbol{O} & & \boldsymbol{u}\left(\phi^{\prime(r)}\right)
\end{array}\right]
\end{aligned}
$$

$\boldsymbol{u}$ signifying $\boldsymbol{u}=\exp [-V / R T]$.

In the same way, we defined the matrix $\boldsymbol{U}(\psi, \varphi)$ for interaction about $\left(\phi_{i-1}, \varphi_{i}\right)$. The interaction energy, in this case, may be given by

$$
\begin{aligned}
& V\left(\psi_{i-1}, \varphi_{i}\right)=V\left(\psi_{i-1}^{\prime}, \phi_{i-1}^{\prime \prime}, \varphi_{i}\right) \\
& =v\left(\psi_{i-1}^{\prime \prime}\right)+V\left(\varphi_{i}\right)+V\left(\psi_{i-1}^{\prime}, \varphi_{i}\right)
\end{aligned}
$$




\section{S. TANAKa and A. NAKaJIMA}

where, $V\left(\varphi_{i}\right)$ and $V\left(\psi_{i-1}^{\prime}, \varphi_{i}\right)$ are the interaction energies about $\varphi_{i}$ and $\left(\psi_{i-1}^{\prime}, \varphi_{i}\right)$, and $v\left(\psi_{?-1}^{\prime \prime}\right)$ is the torsional energy about the imide bond. In the following, $\boldsymbol{U}\left(\varphi_{i-1}, \phi_{i-1}\right)$ and $\boldsymbol{U}\left(\psi_{i-1}, \varphi_{i}\right)$ will be discussed in some detail.

Determination of $\boldsymbol{U}\left(\varphi_{i-1}, \phi_{i-1}\right)$ and $\boldsymbol{U}\left(\psi_{i-1}, \varphi_{i}\right)$

$\boldsymbol{U}\left(\varphi_{i-1}, \phi_{i-1}\right)$ : When $\phi_{i-2}^{\prime \prime}$ and $\phi_{i-1}^{\prime \prime}$ were fixed at trans conformation, we evaluated $V\left(\varphi_{i-1}\right.$, $\psi_{i-1}$ ) from eq. (36) and defined the corresponding statistical weight matrix as $\boldsymbol{U}_{t t}{ }^{*}$

$$
\boldsymbol{U}(\varphi, \psi)=\boldsymbol{U}\left(\varphi_{i-1}, \phi_{i-1}\right)=\boldsymbol{U}_{t t}{ }^{*}
$$

When a cis imide bond was included, we defined $\boldsymbol{U}_{t c}{ }^{*}$ and $\boldsymbol{U}_{c t}{ }^{*}$ as follows.

$$
\boldsymbol{U}\left(\varphi_{i-1}, \psi_{i-1}\right)=\left\{\begin{array}{l}
\boldsymbol{U}_{t c}^{*} \\
\boldsymbol{U}_{c t}^{*}
\end{array}\right.
$$

Eqs. (42-a) and (42-b) corresponded to the cases where $\psi_{i-2}^{\prime \prime}=$ trans and $\psi_{i-1}^{\prime \prime}=c i s$, and where $\psi_{i-2}^{\prime \prime}=c i s$ and $\psi_{i-1}^{\prime \prime}=$ trans, respectively.

$\boldsymbol{U}\left(\psi_{i-1}, \varphi_{i}\right):$ By the use of Eq. 40 , we defined the following matrices in obedience to the conformations.

$$
\boldsymbol{U}\left(\psi_{i-1}, \varphi_{i}\right)= \begin{cases}\sigma_{t} \boldsymbol{U}_{t}^{* *} & \left(\psi_{i-1}^{\prime \prime}=\text { trans }\right) \\ \sigma_{c} U_{c}^{* *} & \left(\psi_{i-1}^{\prime \prime}=\text { cis }\right)\end{cases}
$$

in which $\sigma_{t}$ and $\sigma_{c}$ were given by

$$
\exp \left[-\frac{v\left(\psi_{i-1}^{\prime \prime}\right)}{R T}\right]= \begin{cases}\sigma_{t} & \left(\psi_{i-1}^{\prime \prime}=\text { trans }\right) \\ \sigma_{c} & \left(\psi_{i-1}^{\prime \prime}=\text { cis }\right)\end{cases}
$$

For trans conformation of $\phi_{i-1}^{\prime \prime}$, as mentioned in the previous section, $V\left(\psi_{i-1}^{\prime}, \varphi_{i}\right)$ became zero, and $\boldsymbol{U}_{t}{ }^{* *}$ was given by a diagonal matrix with $V(\varphi)$ 's for $r$ discrete values of $\varphi$ as the diagnoal elements. Contrarily, for the cis conformation of $\psi_{i-1}^{\prime \prime}, V\left(\psi_{i-1}^{\prime}, \varphi_{i}\right)$ was not zero but corresponded to the interaction energy between $\left(\mathrm{C}_{i-1}^{\alpha}-\mathrm{H}_{2}\right)$ and $\left(\mathrm{C}_{i}{ }^{\alpha}-\mathrm{H}_{2}\right)$.

\section{Conformational Partition Fucntion}

Up to date, little has been known about distribution of cis and trans imide bonds in the chain. In this paper, we assume that cis imide bonds do not exist successively in the chain; i.e., two neighboring imide bonds on both sides of a given cis imide bond should be in trans conformation. In other words, we were concerned with imide triad sequences: trans-trans-trans, trans-trans-cis, cis-trans-trans, cis-trans-cis, and trans-cis-trans.
On this basis, it was necessary to formulate a statistical weight matrix which also took into account the arrangements of two successive imide bonds.

We then designated the $\mathrm{C}_{i-1}-\mathrm{N}_{i}$ and $\mathrm{C}_{i}-\mathrm{N}_{i+1}$ bonds as the $(i-1)$-th imide bond and the $i$-th imide bond, respectively (see Figure 4). And we constructed the matrix $\boldsymbol{s}$ of order $\boldsymbol{r}$ by the product of $\boldsymbol{U}\left(\psi_{i-1}, \varphi_{i}\right)$ and $\boldsymbol{U}\left(\varphi_{i}, \psi_{i}\right)$. The matrix $\boldsymbol{s}$ was defined as follows, according to the arrangements of two successive imide bonds.

$$
\begin{aligned}
\boldsymbol{s}_{t t} & =\boldsymbol{U}\left(\phi_{i-1}, \varphi_{i} ; \operatorname{trans} \phi_{i-1}^{\prime \prime}\right) \boldsymbol{U}\left(\varphi_{i}, \phi_{i} ; \operatorname{trans}{\psi_{i}}^{\prime \prime}\right) \\
& =\sigma_{t} \boldsymbol{U}_{t}{ }^{* *} \boldsymbol{U}_{t t}{ }^{*} \\
\boldsymbol{s}_{t c} & =\boldsymbol{U}\left(\phi_{i-1}, \varphi_{i} ; \operatorname{trans} \phi_{i-1}^{\prime \prime}\right) \boldsymbol{U}\left(\varphi_{i}, \phi_{i} ; \operatorname{cis}{\phi_{i}}^{\prime \prime}\right) \\
& =\sigma_{t} \boldsymbol{U}_{t}{ }^{* *} \boldsymbol{U}_{t c}{ }^{*} \\
\boldsymbol{s}_{c t} & =\boldsymbol{U}\left(\phi_{i-1}, \varphi_{i} ; \operatorname{cis} \phi_{i-1}^{\prime \prime}\right) \boldsymbol{U}\left(\varphi_{i}, \phi_{i} ; \operatorname{trans} \phi_{i}{ }^{\prime \prime}\right) \\
& =\sigma_{c} \boldsymbol{U}_{c}{ }^{* *} \boldsymbol{U}_{c t}{ }^{*}
\end{aligned}
$$

Further, a new matrix $\boldsymbol{S}$ of order $2 r$ was constructed from $\boldsymbol{s}_{t t}, \boldsymbol{s}_{t c}, \boldsymbol{s}_{c t}$ and $\boldsymbol{s}_{c c}(=0)$, by arranging $(i-1)$-th imide conformations on the rows and $i$-th imide conformations on the columns.

$$
\boldsymbol{S}=\left[\begin{array}{rr}
\boldsymbol{s}_{t t} & \boldsymbol{s}_{t c} \\
\boldsymbol{s}_{c t} & O
\end{array}\right]
$$

Thus the conformational partition function $Z$ of the chain composed of $n$ imide bonds was given by

$$
\boldsymbol{Z}=\boldsymbol{J}^{T} \boldsymbol{S}_{1} \boldsymbol{S}^{n} \boldsymbol{S}_{n} \boldsymbol{J}
$$

where,

$$
\begin{gathered}
\boldsymbol{S}_{1}=\left[\begin{array}{ll}
\boldsymbol{s}_{t} & O \\
O & \boldsymbol{s}_{c}
\end{array}\right] \\
\boldsymbol{s}_{t}=\boldsymbol{U}\left(\varphi_{1}, \phi_{1} ; \text { trans } \phi_{1}{ }^{\prime \prime}\right)=\boldsymbol{U}_{o t}{ }^{*} \\
\boldsymbol{s}_{c}=\boldsymbol{U}\left(\varphi_{1}, \phi_{1} ; \text { cis } \phi_{1}{ }^{\prime \prime}\right)=\boldsymbol{U}_{o c}{ }^{*} \\
\boldsymbol{S}_{n}=\left[\begin{array}{ll}
\boldsymbol{s}_{t t} & \boldsymbol{s}_{t c} \\
\boldsymbol{s}_{c t} & O
\end{array}\right] \\
\boldsymbol{s}_{t t}=\boldsymbol{s}_{c t}=\sigma_{t} \boldsymbol{U}_{t}{ }^{* *} \\
\boldsymbol{s}_{t c}=\sigma_{c} \boldsymbol{U}_{c}{ }^{* *}
\end{gathered}
$$

and $\boldsymbol{J}$ was the column matrix of order $2 r$ with all elements unity and $\boldsymbol{J}^{T}$ was its transpose.

$$
\boldsymbol{J}^{T}=(1,1, \ldots, 1)
$$

Mean Square Unperturbed End-to-End Distance

To evaluate the characteristic ratio from the 
conformational statistical weight matrices, it was necessary to average the transformation matrices.

Let the transformation matrix which transforms the co-ordinate system attached to $l_{b, i-1}$ to that attached to $\boldsymbol{l}_{a, i-1}$ be $\boldsymbol{T}_{2}$, and that relating to the transformation from $l_{a, i}$ to $l_{b, i-1}$ be $T_{1}$. At this stage, we adopted the method used by Flory ${ }^{16}$ and Flory and Jernigan ${ }^{17}$; i.e., we used the quantity $g$ defined by them.

$$
\boldsymbol{g}=\left[\begin{array}{ccc}
\boldsymbol{U} & \boldsymbol{U} \times \boldsymbol{l}^{T} \boldsymbol{T}^{*} & O \\
O & \boldsymbol{U} \times \boldsymbol{E} \boldsymbol{T}^{*} & \boldsymbol{U} \times \boldsymbol{l} \\
O & O & \boldsymbol{U}
\end{array}\right]
$$

$T^{*}$, which was analogous to Eq. 22 in nature, was evaluated from $\boldsymbol{T}_{2}$ and $\boldsymbol{T}_{1}$ by the method given by Flory $^{16,17}$.

In accordance with the conformations, $U$ was replaced by $\sigma_{t} U_{t}{ }^{* *}, \sigma_{c} U_{c}{ }^{* *}, U_{t t}{ }^{*}, U_{c t}{ }^{*}$, or $U_{t c}{ }^{*}$, and $\boldsymbol{l}$ was also replaced by corresponding $l_{a}$ or $\boldsymbol{l}_{b}$; thus $\boldsymbol{g}_{t}{ }^{* *}, \boldsymbol{g}_{c}{ }^{* *}, \boldsymbol{g}_{t t}{ }^{*}, \boldsymbol{g}_{c t}{ }^{*}$ and $\boldsymbol{g}_{t c}{ }^{*}$ were obtained from Eq. 55. Then we made matrices $\boldsymbol{G}_{t t}, \boldsymbol{G}_{t c}$, and $\boldsymbol{G}_{c t}$, by analogy from Eqs. $45-\mathrm{a}, 45-\mathrm{b}$, and 45-c, respectively.

$$
\begin{aligned}
\boldsymbol{G}_{t t} & =\boldsymbol{g}_{t}{ }^{* *} \boldsymbol{g}_{t t}{ }^{*} \\
\boldsymbol{G}_{t c} & =\boldsymbol{g}_{t}{ }^{* *} \boldsymbol{g}_{t c}{ }^{*} \\
\boldsymbol{G}_{c t} & =\boldsymbol{g}_{c}{ }^{* *} \boldsymbol{g}_{c t}{ }^{*}
\end{aligned}
$$

and finally constructed the matrix $K$ composed of these matrices.

$$
\boldsymbol{K}=\left[\begin{array}{cc}
\boldsymbol{G}_{t t} & \boldsymbol{G}_{t c} \\
\boldsymbol{G}_{c t} & O
\end{array}\right]
$$

In conclusion, the characteristic ratio was given by the equation:

$$
\begin{aligned}
\frac{\left\langle\boldsymbol{R}_{0}{ }^{2}\right\rangle}{n^{\prime} \bar{l}^{2}}=1+\frac{2}{Z n^{\prime} \bar{l}^{2}}\left[\boldsymbol{J}^{* T} 0 \ldots 0 \boldsymbol{J}^{* T} 0 \ldots 0\right] \\
\\
\times \boldsymbol{K}_{1} \boldsymbol{K}^{n} \boldsymbol{K}_{n}\left[\begin{array}{c}
0 \\
\vdots \\
\boldsymbol{J} \times \boldsymbol{l}_{n+1} \\
0 \\
\vdots \\
0 \\
\boldsymbol{J} \times \boldsymbol{l}_{n+1} \\
\boldsymbol{J}
\end{array}\right]
\end{aligned}
$$

In Eq. 58, $K_{1}$ was evaluated from Eqs. 48-50, taking into account that $\boldsymbol{G}_{t}=\boldsymbol{g}_{o t}{ }^{*}, \boldsymbol{G}_{c}=\boldsymbol{g}_{0 c}{ }^{*}$; i.e.

$$
\boldsymbol{K}_{1}=\left[\begin{array}{cc}
\boldsymbol{g}_{o t}{ }^{*} & O \\
O & \boldsymbol{g}_{o c}{ }^{*}
\end{array}\right]
$$

Similarly, $\boldsymbol{K}_{n}$ was constructed by taking into account that $\boldsymbol{G}_{t t}=\boldsymbol{G}_{c t}=\boldsymbol{g}_{t}{ }^{* *}$ and $\boldsymbol{G}_{t c}=\boldsymbol{g}_{c}{ }^{* *}$; i.e.

$$
\boldsymbol{K}_{n}=\left[\begin{array}{cc}
\boldsymbol{g}_{t}^{* *} & \boldsymbol{g}_{c}{ }^{* *} \\
\boldsymbol{g}_{t}{ }^{* *} & O
\end{array}\right]
$$

Further, $\boldsymbol{l}_{n+1}$ denoted the bond vector of $\mathrm{N}_{n+1}-$ $\mathrm{C}_{n+1}^{\alpha}, \bar{l}^{2}$ the mean value of $l_{a}{ }^{2}$ and $l_{b}{ }^{2}$,

$$
\bar{l}^{2}=(1 / 2)\left(l_{a}^{2}+l_{b}^{2}\right), \text { and } 2 n^{\prime}=n+1 .
$$

\section{DISCUSSION}

The conformation calculation carried out by assuming the trans conformation for all imide bonds resulted in $\left\langle R_{0}{ }^{2}\right\rangle / n l^{2}=1.46$ when the interactions between nonbonded atoms separated by three and four bonds were taken into account. By considering the interactions covering all of the possible nonbonded atom pairs separated by three, four, and five bonds the characteristic ratio increased slightly up to $\left\langle R_{0}{ }^{2}\right\rangle / n l^{2}=1.53$. This meant that the consideration of only three- and four-bond interactions was sufficient to estimate the characteristic ratio for the chain with all the imide bonds in trans conformation. Further, the characteristic ratio thus obtained was slightly smaller than that $(=1.89)$ calculated by assuming free rotation for bonds except the imide bonds. Though the numerical calculation was not carried out because of the lack of data, the effect of cis imide bonds along with trans imide bonds was also examined theoretically. As mentioned in section II, in this case, the nonbonded atom interactions between $\mathrm{C}_{i-1}^{\alpha}-\mathrm{H}_{2}$ and $\mathrm{C}_{i}{ }^{\alpha}-\mathrm{H}_{2}$ groups were found to be of major importance.

To derive the numerial results on the characteristic ratio in the presence of cis imide bonds, more experimental data are necessary.

With regard to poly( $\mathrm{N}$-methyl glycine), experimentally, only the data reported by Fessler and Ogston $^{18,19}$ are available. By the use of the method proposed by Stockmayer and Fixman ${ }^{20}$, we obtained $\left\langle R_{0}{ }^{2}\right\rangle / n l^{2}=1.8 \pm 0.2$ from their data on the intrinsic viscosities and molecular weights. This experimental value was slightly 


\section{S. TANAKa and A. NAKaJima}

Table V. Unperturbed characteristic ratios of various polyamino acids

\begin{tabular}{|c|c|c|c|}
\hline \multirow{2}{*}{ Polyamino acid } & \multirow{2}{*}{$\begin{array}{l}\text { Chemical } \\
\text { structure }\end{array}$} & \multicolumn{2}{|c|}{$\left\langle R_{0}{ }^{2}\right\rangle / n l^{2}$} \\
\hline & & Calc. & Obs. \\
\hline Polyglycine & $\begin{array}{r}\mathrm{O} \\
-\mathrm{NH}-\mathrm{CH}_{2}-\mathrm{C}- \\
\mathrm{O}\end{array}$ & $\begin{array}{l}2.16^{8} \\
1.79^{8}\end{array}$ & - \\
\hline $\begin{array}{l}\text { Poly(N-methyl } \\
\text { glycine) }\end{array}$ & $\begin{array}{l}-\mathrm{N}-\mathrm{CH}_{2}-\stackrel{\|}{\mathrm{C}}- \\
\stackrel{\mathrm{I}}{\mathrm{C}} \mathrm{H}_{3}\end{array}$ & $\begin{array}{l}1.53 \\
1.46\end{array}$ & $1.8 \pm 0.2^{18}$ \\
\hline Poly-L-alanine & $\begin{array}{c}\stackrel{\mathrm{O}}{\|} \\
-\mathrm{NH}-\mathrm{CH}-\mathrm{C}- \\
\stackrel{\mathrm{C}}{\mathrm{C}} \mathrm{H}_{3}\end{array}$ & $9.27^{8}$ & \\
\hline $\begin{array}{l}\text { Poly- } \alpha \text {-L-amino- } \\
\text { acid }\end{array}$ & $\begin{array}{c}\stackrel{\mathrm{O}}{\Perp} \\
-\mathrm{NH}-\mathrm{CH}-\stackrel{\mathrm{C}}{\mathrm{C}}- \\
\stackrel{\mathrm{C}}{\mathrm{C}} \mathrm{H}_{2} \\
1 \\
\mathrm{R}\end{array}$ & $9.13^{1}$ & \\
\hline $\mathrm{PBLA}^{7}$ & & & 9.6 \\
\hline Na-PLGA ${ }^{7}$ & & & 8.8 \\
\hline $\mathrm{PLL} \mathrm{HBr}^{7}$ & & & 8.6 \\
\hline $\mathrm{PBLG}^{7}$ & & & 8.8 \\
\hline PMLG $^{21}$ & & & 9.9 \\
\hline
\end{tabular}

PBLA: poly- $\beta$-benzyl-L-aspartate, PLGA: poly-L-glutamic acid, PLL: poly-L-lysine, PBLG: poly- $\gamma$-benzyl-L-glutamate, PMLG: poly- $\gamma$-methyl-L-glutamate.

higher than the calculated value for chains with all imide units in trans conformation. The difference between them should be further examined by taking into account the effect of cis imide units among the chain.

In Table V, these results are listed together with the results on polyglycine, poly-L-alanine and poly- $\alpha$-L-amino acids.

In the case of polyglycine, the parent polymer of poly( $\mathrm{N}$-methyl glycine), the calculated characteristic ratios (2.16 and 1.79) are rather close to that of a chain having free rotation about all $\mathrm{N}-\mathrm{C}^{\alpha}$ and $\mathrm{C}^{\alpha}-\mathrm{C}$ bonds, and much smaller than those of poly-L-alanine and poly- $\alpha$-L-amino acids. The less extended character of the polyglycine chain has been concluded to result from the chain symmetry ${ }^{9}$. Poly(N-methyl glycine) is the same in chemical composition as poly-L-alanine (the former is $\mathrm{N}$-substituted and the latter is $\alpha$-substituted amino acid polymer). Nevertheless, the characteristic ratio of the latter is much higher than the former. It should be noticed that $\alpha$ - substitution in polyglycine chain makes the chain dimenison larger than the case of $\mathrm{N}$-substitution, as long as all imide (or amide) bonds are assumed to be in trans conformation. For detailed calculation on the case of coexistence of cis imide bonds, more experimental data should be accumlated.

The computations were carried out on the KDC-II computer at the Kyoto University Computation Center.

This work was partly supported by the Takeda Science Foundation.

\section{REFERENCES}

1. D.A. Brant and P.J. Flory, J. Amer. Chem. Soc., 87, 2791 (1965).

2. S. Lifson, J. Chem. Phys., 30, 964 (1959).

3. K. Nagai, ibid., 31, 1169 (1959).

4. C. A. J. Hoeve, ibid., 32, 888 (1960).

5. E. Ising, Z. Phys., 31, 253 (1925).

6. H. A. Kramers and G. H. Wannier, Phys. Rev., 60, 252 (1941).

7. D.A. Brant and P.J. Flory, J. Amer. Chem. Soc., 87, 2788 (1965).

8. D. A. Brant, W. G. Miller, and P. J. Flory, J. Mol. Biol., 23, 47 (1967).

9. W. G. Miller, D. A. Brant and P. J. Flory, ibid., 23, 67 (1967).

10. P. R. Schimmel and P. J. Flory, ibid., 34, 105 (1968).

11. A. N. Glazer and K. Rosenheck, J. Biol. Chem., 237, 3674 (1962).

12. F. A. Bovery, J. J. Ryan and F. P. Hood, Macromolecules, 1, 305 (1968).

13. R. A. Scott and H. A. Scheraga, J. Chem. Phys., 45, 2091 (1966).

14. W. G. Crewther, J. Polym. Sci., Part A, 2, 123 (1964).

15. I. Suzuki, Bull. Chem. Soc. Japan, 35, 540 (1962).

16. P. J. Flory, Proc. Natl. Acad. Sci., 51, 1060 (1964).

17. P. J. Flory and R. L. Jernigan, J. Chem. Phys., 42, 3509 (1965).

18. J. H. Fessler and A. G. Ogston, Trans. Faraday Soc., 47, 667 (1951).

19. C. H. Bamford, A. Elliott, and W. E. Hanby, "Synthetic Polypeptides", Academic Press, New York (1956).

20. W. H. Stockmayer and M. Fixman, J. Polym. Sci., Part C, No. 1, 137 (1963).

21. S. Tanaka and A. Nakajima, unpublished data. 
Conformation of Poly(N-Methyl Glycine) Random Chains

\section{Appendix}

Table VI. Non-bonded atom pairs and vectors

\begin{tabular}{|c|c|c|}
\hline \multicolumn{2}{|c|}{ Atom pair } & Sum of bond vector \\
\hline $\mathrm{O}_{i-1}$ & $\mathrm{H}_{1}{ }^{\alpha}$ & $l^{\prime \prime}+T^{\prime \prime} l^{\prime \prime \prime}-l_{i-1}^{(\mathrm{O})}+T^{\prime \prime} T^{\prime \prime \prime} l_{i}\left(\mathrm{H}_{1}\right)$ \\
\hline $\mathrm{O}_{i-1}$ & $\mathrm{H}_{2}{ }^{\alpha}$ & $l^{\prime \prime}+T^{\prime \prime} l^{\prime \prime \prime}-l_{i-1}^{(0)}+T^{\prime \prime} T^{\prime \prime \prime} l_{i}\left(\mathrm{H}_{2}\right)$ \\
\hline $\mathrm{O}_{i-1}$ & $\mathrm{C}_{i}$ & $l^{\prime \prime}+T^{\prime \prime} l^{\prime \prime \prime}-l_{i-1}^{(0)}+T^{\prime \prime} T^{\prime \prime \prime} l^{\prime}$ \\
\hline $\mathrm{O}_{i-1}$ & $\mathrm{O}_{i}$ & $l^{\prime \prime}+T^{\prime \prime} l^{\prime \prime \prime}-l_{i-1}^{(0)}+T^{\prime \prime} T^{\prime \prime \prime} l^{\prime}+T^{\prime \prime} T^{\prime \prime \prime} T^{\prime} l_{i}^{(0)}$ \\
\hline $\mathbf{C}_{i-1}$ & $\mathrm{H}_{1}^{\alpha}$ & $l^{\prime \prime}+T^{\prime \prime} l^{\prime \prime \prime}+T^{\prime \prime} T^{\prime \prime \prime} l_{i}^{\left(\mathrm{H}_{1}\right)}$ \\
\hline $\mathrm{C}_{i-1}$ & $\mathrm{H}_{2}{ }^{\alpha}$ & $l^{\prime \prime}+T^{\prime \prime} l^{\prime \prime \prime}+T^{\prime \prime} T^{\prime \prime \prime} l_{i}{ }^{\left(\mathrm{H}_{2}\right)}$ \\
\hline $\mathrm{C}_{i-1}$ & $\mathrm{C}_{i}$ & $l^{\prime \prime}+T^{\prime \prime} l^{\prime \prime \prime}+T^{\prime \prime} T^{\prime \prime \prime} l^{\prime}$ \\
\hline $\mathrm{C}_{i-1}$ & $\mathrm{O}_{i}$ & $l^{\prime \prime}+T^{\prime \prime} l^{\prime \prime \prime}+T^{\prime \prime} T^{\prime \prime \prime} l^{\prime}+T^{\prime \prime} T^{\prime \prime \prime} T^{\prime} l_{i}^{(0)}$ \\
\hline $\mathbf{N}_{i-1}$ & $\mathrm{O}_{i}$ & $l^{\prime \prime \prime}+T^{\prime \prime \prime} l^{\prime}+T^{\prime \prime \prime} T^{\prime} l_{i}{ }^{(0)}$ \\
\hline $\mathrm{N}_{i-1}$ & $\mathbf{N}_{i}$ & $l^{\prime \prime \prime}+T^{\prime \prime \prime} l^{\prime}+T^{\prime \prime \prime} T^{\prime} l^{\prime \prime}$ \\
\hline $\mathbf{N}_{i-1}$ & $\mathrm{C}_{i}^{\mathrm{N}}$ & $l^{\prime \prime \prime}+T^{\prime \prime \prime} l^{\prime}+T^{\prime \prime \prime} T^{\prime} l^{\prime \prime}+T^{\prime \prime \prime} T^{\prime} T^{\prime \prime} l_{i}^{(\mathrm{N})}$ \\
\hline $\mathrm{C}_{i-1}^{N}$ & $\mathrm{H}_{1}^{\alpha}$ & $-l_{i-1}^{(\mathrm{N})}+l^{\prime \prime \prime}+T^{\prime \prime \prime} l_{i}^{\left(\mathrm{H}_{1}\right)}$ \\
\hline $\mathrm{C}_{i-1}^{\mathrm{N}}$ & $\mathrm{H}_{2}^{\alpha}$ & $-l_{i-1}^{(\mathrm{N})}+l^{\prime \prime \prime}+T^{\prime \prime \prime} l_{i}^{\left(\mathrm{H}_{2}\right)}$ \\
\hline $\mathrm{C}_{i-1}^{\mathrm{N}}$ & $\mathrm{C}_{i}$ & $-l_{i-1}^{(\mathrm{N})}+l^{\prime \prime \prime}+T^{\prime \prime \prime} l^{\prime}$ \\
\hline $\mathrm{C}_{i-1}^{\mathrm{N}}$ & $\mathbf{O}_{i}$ & $-l_{i=1}^{(\mathrm{N})}+l^{\prime \prime \prime}+T^{\prime \prime \prime} l^{\prime}+T^{\prime \prime \prime} T^{\prime} l_{i}^{(0)}$ \\
\hline $\mathrm{C}_{i-1}^{N}$ & $\mathbf{N}_{i}$ & $-l_{i-1}^{(\mathrm{N})}+l^{\prime \prime \prime}+T^{\prime \prime \prime} l^{\prime}+T^{\prime \prime \prime} T^{\prime} l^{\prime \prime}$ \\
\hline $\mathrm{C}_{i-1}^{\mathrm{N}}$ & $\mathrm{C}_{i}^{\mathrm{N}}$ & $-l_{i-1}^{(\mathrm{N})}+l^{\prime \prime \prime}+T^{\prime \prime \prime} l^{\prime}+T^{\prime \prime \prime} T^{\prime} l^{\prime \prime}+T^{\prime \prime \prime} T^{\prime} T^{\prime \prime} l_{i}^{(\mathrm{N})}$ \\
\hline $\mathrm{C}_{i}^{\alpha}$ & $\mathrm{C}_{i^{\mathrm{N}}}$ & $l^{\prime}+T^{\prime} l^{\prime \prime}+T^{\prime} T^{\prime \prime} l_{i}^{(\mathrm{N})}$ \\
\hline $\mathrm{H}_{1}^{\alpha}$ & $\mathrm{O}_{i}$ & $-\boldsymbol{l}_{i}^{\left(\mathrm{H}_{1}\right)}+\boldsymbol{l}^{\prime}+\boldsymbol{T}^{\prime} \boldsymbol{l}_{i^{(\mathrm{O})}}$ \\
\hline $\mathrm{H}_{1}{ }^{\alpha}$ & $\mathbf{N}_{i}$ & $-\boldsymbol{l}_{i}^{\left(\mathrm{H}_{1}\right)}+\boldsymbol{l}^{\prime}+T^{\prime} \boldsymbol{l}^{\prime \prime}$ \\
\hline $\mathrm{H}_{1}^{\alpha}$ & $\mathrm{C}_{i^{\mathrm{N}}}^{\mathrm{N}}$ & $-l_{i}^{\left(\mathrm{H}_{1}\right)}+l^{\prime}+T^{\prime} l^{\prime \prime}+T^{\prime} T^{\prime \prime} l^{\prime \prime \prime}$ \\
\hline $\mathrm{H}_{2}{ }^{\alpha}$ & $\mathrm{O}_{i}$ & $-l_{i}^{\left(\mathrm{H}_{2}\right)}+l^{\prime}+T^{\prime} l_{i}{ }^{(0)}$ \\
\hline $\mathrm{H}_{2}^{\alpha}$ & $\mathbf{N}_{i}$ & $-l_{i}^{\left(\mathrm{H}_{2}\right)}+l^{\prime}+T^{\prime} l^{\prime \prime}$ \\
\hline $\mathrm{H}_{2}{ }^{\alpha}$ & $\mathrm{C}_{i} \mathrm{~N}$ & $-l_{i}^{\left(\mathrm{H}_{2}\right)}+l^{\prime}+T^{\prime} l^{\prime \prime}+T^{\prime} \boldsymbol{T}^{\prime \prime} \boldsymbol{l}_{i}^{(\mathrm{N})}$ \\
\hline $\mathrm{C}_{i}$ & $\mathrm{H}_{i-1}^{k}$ & $-l_{i-1}^{(k)}+l^{\prime \prime \prime}+T^{\prime \prime \prime} l^{\prime} \quad(k=1,2,3)$ \\
\hline $\mathrm{O}_{i}$ & $\mathrm{H}_{i-1}^{k}$ & $-l_{i-1}^{(k)}+l^{\prime \prime \prime}+T^{\prime \prime \prime} l^{\prime}+T^{\prime \prime \prime} T^{\prime} l_{i}^{(0)}$ \\
\hline $\mathbf{N}_{i}$ & $\mathrm{H}_{i-1}^{k}$ & $-l_{i-1}^{(k)}+l^{\prime \prime \prime}+T^{\prime \prime \prime} l^{\prime}+T^{\prime \prime \prime} T^{\prime} l^{\prime \prime}$ \\
\hline $\mathrm{C}_{i^{\mathrm{N}}}^{\mathrm{N}}$ & $\mathrm{H}_{i-1}^{k}$ & $-l_{i-1}^{(k)}+l^{\prime \prime \prime}+T^{\prime \prime \prime} l^{\prime}+T^{\prime \prime \prime} T^{\prime} l^{\prime \prime}+T^{\prime \prime \prime} T^{\prime} T^{\prime \prime} l_{i}^{(N)}$ \\
\hline $\mathrm{H}_{i}{ }^{1}$ & $\mathrm{H}_{i-1}^{k}$ & $-l_{i-1}^{(k)}+l^{\prime \prime \prime}+T^{\prime \prime \prime} l^{\prime}+T^{\prime \prime \prime} T^{\prime} l^{\prime \prime}+T^{\prime \prime \prime} T^{\prime} T^{\prime \prime} l_{i}^{(1)}$ \\
\hline $\mathrm{H}_{i}{ }^{2}$ & $\mathrm{H}_{i-1}^{k}$ & $-l_{i-1}^{(k)}+l^{\prime \prime \prime}+T^{\prime \prime \prime} l^{\prime}+T^{\prime \prime \prime} T^{\prime} l^{\prime \prime}+T^{\prime \prime \prime} T^{\prime} T^{\prime \prime} l_{i}^{(2)}$ \\
\hline $\mathrm{H}_{i}{ }^{3}$ & $\mathrm{H}_{i-1}^{k}$ & $-l_{i-1}^{(k)}+l^{\prime \prime \prime}+T^{\prime \prime \prime} l^{\prime}+T^{\prime \prime \prime} T^{\prime} l^{\prime \prime}+T^{\prime \prime \prime} T^{\prime} T^{\prime \prime} l_{i}^{(3)}$ \\
\hline $\mathrm{N}_{i-1}$ & $\mathrm{H}_{i}^{k}$ & $l^{\prime \prime \prime}+T^{\prime \prime \prime} l^{\prime}+T^{\prime \prime \prime} T^{\prime} l^{\prime \prime \prime}+T^{\prime \prime \prime} T^{\prime} T^{\prime \prime} l_{i}^{(k)}$ \\
\hline$C_{i-1}^{N}$ & $\mathrm{H}_{i}{ }^{k}$ & $-l_{i-1}^{(\mathrm{N})}+l^{\prime \prime \prime}+T^{\prime \prime \prime} l^{\prime}+T^{\prime \prime \prime} T^{\prime} l^{\prime \prime}+T^{\prime \prime \prime} T^{\prime} T^{\prime \prime} l_{i}^{(k)}$ \\
\hline
\end{tabular}

